\title{
Migración, trabajo y derechos precarios: perspectivas histórica y actual
}

\author{
Stephen Castles \\ (traducción del inglés de Luis Rodolfo Morán Quiroz)
}

Resumen. El desarrollo del mercado mundial capitalista siempre ha estado vinculado con la diferenciación de los trabajadores y con el uso de la migración para generar formas de «mano de obra no libre»: esclavitud, trabajadores por contrato, trabajadores huéspedes, trabajadores forzados, trabajadores indocumentados y demás. La negación diferenciada de derechos iguales se ha fundamentado en el género, la raza, la etnia, el estatus legal, los orígenes nacionales y en la ideología del capital humano. Este artículo abordará brevemente los antecedentes históricos y luego se enfocará en los modos cambiantes de diferenciación, contrastando los sistemas de reclutamiento de mano de obra del periodo de 1945 a los años setenta con la época de la globalización y la creación del mercado global de fuerza de trabajo.

Palabras clave: migración internacional, historia de la migración, derechos humanos, crisis, globalización neoliberal.

\begin{abstract}
Aвstract. The development of the capitalist world market has always been linked to differentiation of workers and the use of migration to create various forms of «unfree labour»: slavery, indentured workers, guestworkers, forced labourers, undocumented workers and so on. The differential denial of equal rights has been based on gender, race, ethnicity, legal status, national origins and on the ideology of human capital. This paper will briefly address historical antecedents, and then focus on changing modes of differentiation, contrasting the labor recruitment systems of the 1945-1970s period with the epoch of globalization and the creation of a global labor market. Various forms of labor differentiation and denial of rights will be examined.
\end{abstract}

KEYwORDs: international migration, history of migration, human rights, crisis, neoliberal globalization.

Stephen Castles es profesor honorario del Instituto Internacional de Migración de la Universidad de Oxford y dirige la Cátedra de Sociología de la Universidad de Sydney. 


\section{INTRODUCCIÓN}

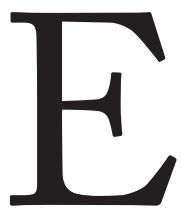
1 tema central de este artículo es la bistoria de la inequidad en los mercados capitalistas de fuerza de trabajo y cómo la inequidad ha evolucionado en diferentes épocas del desarrollo capitalista. El énfasis se ubica en los cambiantes modos de diferenciación de los trabajadores que brindan oportunidades desiguales en la competencia dentro del mercado. Algunos autores han utilizado el término trabajo no libre (unfree labour) para referirse a este fenómeno; otros aluden a negación de los derechos bumanos y laborales; más recientemente otros analistas hablan de precariedad o trabajo precario. Todos estos términos son útiles. Para mí, el tema principal es el de los mecanismos que llevan a la diferenciación y las ideologías utilizadas para legitimarlos, en vista del hecho de que van en contra de un principio central del capitalismo liberal: la libertad, cuya connotación estriba en que los individuos pueden maximizar sus beneficios y que, como participantes en el mercado, tienen igualdad de derechos y oportunidades. Esa igualdad nunca se ha logrado en la práctica.

Pero permítaseme comenzar con algunas de las incógnitas que ha lanzado la crisis económica global (CEG) desde 2008:

1) En los países de la Organización para la Cooperación y el Desarrollo Económicos (OCDE), el desempleo de los trabajadores nacidos en el extranjero se incrementó a un ritmo que duplica el de los trabajadores nacidos en esos países en 2008-2009. Pero el empleo de los nacidos en el extranjero se incrementó en 5\% de 2008 a 2010, mientras que el empleo de los nacidos en el país decayó en 2.2\% (ocDe, 2011: 74-75). ¿Cómo podemos explicar el incremento simultáneo de los empleados que nacieron en el extranjero y el desempleo? ¿Qué significa?

2) Los hombres inmigrantes en los países de la OCDE se vieron mucho más afectados por el desempleo que las mujeres inmigrantes. Las mujeres inmigrantes 
incrementaron su participación en la fuerza de trabajo y tuvieron tasas más bajas de desempleo (ocDE, 2011: 78-81). ¿Por qué pasó eso? ¿Es reflejo de un mejoramiento en la posición de las mujeres migrantes en el mercado de trabajo?

3) En conjunto, la CEG afectó a las viejas economías industriales — notablemente a los países de la OCDE, más que a los países emergentes en Asia y América Latina (Phillips, 2011). ¿Esto significa que existe un cambio en los patrones migratorios globales?

Regresaré a estas cuestiones más adelante. La razón para mencionarlas aquí consiste en mostrar la complejidad de la diferenciación laboral, que puede derivar en resultados inesperados. Parece sorprendente que tanto el desempleo como el empleo de los migrantes se incrementaran al mismo tiempo. De igual manera, tendemos a pensar que las mujeres —en especial las mujeres migrantes- están peor en el trabajo: ¿los hallazgos referidos se contraponen a esta visión? ¿Por qué las economías más ricas se vieron más afectadas por la CEG que las intermedias? Muchos de los lectores conocen las razones de estos cambios, pero necesitamos una teoría de la diferenciación laboral y su papel en la legitimación y la administración de las contradicciones del capitalismo para comprender plenamente esas tendencias.

\section{LA DIFERENCIACIÓN LABORAL}

EN LA HISTORIA DEL CAPITALISMO

Es frecuente ver a la libertad individual como uno de los grandes logros morales del capitalismo, en contraste con sociedades anteriores en donde la libertad estaba restringida por lazos tradicionales, así como en las más recientes sociedades socialistas en las cuales los trabajadores eran controlados por poderosas burocracias. Pero, como mostrara Robin Cohen en su libro The New Helots (Cohen, 1987), el capitalismo ha hecho uso tanto de trabajadores libres como no libres en cada etapa de su desarrollo. Los trabajadores mi- 
grantes con frecuencia pueden ser clasificados como trabajadores no libres, ya sea porque son obligados a viajar al lugar en donde se necesita su fuerza de trabajo, o porque se les niegan los derechos de que gozan otros trabajadores y por ende no pueden competir bajo condiciones de igualdad. Aun cuando la migración es voluntaria, la discriminación institucional e informal puede limitar la libertad y la igualdad de los trabajadores afectados. Es claro que la libertad y la igualdad no son categorías excluyentes: existen grados de no libertad y de desigualdad. La diferenciación de la fuerza de trabajo ha sido crucial en cada una de las etapas del desarrollo del capital.

En el periodo del capitalismo mercantil y del colonialismo (siglos $\mathrm{XV}$-XIX), se usaron varias formas de diferenciación de la fuerza de trabajo migrante. Era frecuente que los marinos, soldados y colonos que salieron de Europa a las colonias estuvieran lejos se ser privilegiados. Algunos huían de la persecución religiosa, mientras que otros eran trabajadores por contrato, atados a cierta compañía o amo. Jan Lucassen (1995) ha mostrado que cerca de la mitad de los soldados y los marinos de la Dutch East India Company, en los siglos XVII y XVIII, no eran holandeses sino transmigrantes, principalmente de áreas pobres de Alemania. La mortalidad de estos trabajadores migrantes por naufragios, guerra y enfermedades tropicales era muy alta, pero el servicio en las colonias con frecuencia constituía la única oportunidad de escapar de la pobreza. Algunos de ellos cumplieron sus periodos como trabajadores bajo contrato y se convirtieron en colonos, y era frecuente que prosperaran en el largo plazo.

Desde el siglo Xvir hasta mediados del XIx, la esclavitud fue la principal fuente de fuerza de trabajo para las plantaciones y las minas del Nuevo Mundo (Blackburn, 1988). La esclavitud fue quizá el primer sistema transnacional de reclutamiento de fuerza de trabajo para la acumulación de capital. En el «comercio triangular», barcos cargados con bienes manufacturados, como pistolas o implementos del hogar, zarpaban desde Bristol y Liverpool, Bordeaux y Le Havre, hacia las costas de África Occidental. En ellas, los africanos eran retirados por la fuerza o eran comprados a los jefes locales 
o a los comerciantes a cambio de bienes. Luego los barcos zarpaban hacia el Caribe o hacia Norte o Sudamérica, en donde los esclavos eran vendidos en efectivo; éste era utilizado para comprar los productos de las plantaciones, que eran llevadas a su regreso para ser vendidas en Europa. Se calcula que unos 15 millones de esclavos fueron llevados a América antes de 1850 (Appleyard, 1991). En 1807, se abolió el tráfico de esclavos dentro del imperio británico, aunque la esclavitud misma no fue abolida sino hasta 1834 en las colonias británicas; en 1863 en las colonias holandesas, y en 1865 en los estados del sur de Estados Unidos (Cohen, 1991).

En la segunda mitad del siglo xix, los esclavos fueron reemplazados por trabajadores bajo contrato como la principal fuente de fuerza de trabajo en las plantaciones. Las autoridades coloniales británicas reclutaban trabajadores del subcontinente hindú para las plantaciones de azúcar en el Caribe. Otros estaban empleados en las plantaciones, en las minas y en la construcción del ferrocarril en Malaya, el este de África y Fiji. Los británicos también reclutaron a coolies chinos para Malaya y otras colonias. Las autoridades coloniales holandesas utilizaron mano de obra china en proyectos de construcción en las Indias holandesas orientales. Hasta un millón de trabajadores por contrato fueron reclutados en Japón, principalmente para trabajar en Hawai, Estados Unidos, Brasil y Perú (Shimpo, 1995). Los trabajadores bajo contrato estaban obligados por contratos estrictos de varios años. Los sueldos y las condiciones eran, por lo general, bastante pobres; los trabajadores estaban sujetos a una rígida disciplina y el incumplimiento de los contratos era castigado severamente. Los trabajadores bajo contrato con frecuencia eran más baratos para sus patrones que los esclavos. Por otra parte, el trabajo en ultramar ofrecía una oportunidad de escapar de la pobreza y la represión, como el sistema de castas en India. Muchos trabajadores se quedaron como colonos libres en el este de África, el Caribe, Fiji y otros lugares, donde pudieron obtener tierras o establecer negocios (Cohen, 1995).

Los magnates del azúcar y del tabaco regresaron a Europa occidental buena parte de la riqueza acumulada por medio de las excesivas ganancias de 
la esclavitud y del trabajo bajo contrato, proveyendo el capital que habría de desencadenar las revoluciones industriales de los siglos xviII y xIx. En Gran Bretaña, las ganancias provenientes de las colonias fueron invertidas en nuevas formas de manufactura, así como en la agricultura comercial y los acotamientos de tierra arable para la pastura. Los agricultores desplazados aumentaron las masas urbanas de empobrecidos disponibles como fuerza de trabajo para las nuevas fábricas. A esta clase emergente de trabajadores asalariados pronto se le unieron los artesanos desposeídos, como los tejedores con telares manuales, quienes habían perdido su forma de subsistencia por la competencia que provenía de los nuevos manufactureros. Aquí descansa la base de la nueva clase que fue crucial para la economía industrial británica: el "proletariado libre» que estaba separado de los lazos tradicionales, pero también carecía de la propiedad de los medios de producción. En esta forma de «acumulación primitiva», que proporcionaba la fuerza de trabajo para la revolución industrial, Karl Marx enfatizó los procesos de despojo de los antiguos campesinos y artesanos en Gran Bretaña (Marx, 1976). Pero es importante considerar que el uso de la fuerza de trabajo no libre en las colonias también fue crucial para la acumulación de capital en Gran Bretaña y en otros lugares de Europa.

Sin embargo, pronto surgieron nuevas formas de diferenciación laboral en las economías industriales, cuando se agotó la migración interna ruralurbana y la reproducción de la clase trabajadora urbana se puso en riesgo ante las espantosas condiciones de vida y trabajo. La más cercana colonia de Gran Bretaña, Irlanda, se convirtió en una importante fuente de fuerza de trabajo. La devastación de la agricultura campesina en Irlanda por los terratenientes ausentes y los acotamientos, combinada con la ruina de la industria nacional por la competencia británica, derivó en una extendida pobreza. Las hambrunas de 1822 y 1846-1847 desencadenaron migraciones masivas hacia Gran Bretaña, Estados Unidos y Australia. Para 1851, había más de 700 mil irlandeses en Gran Bretaña (Jackson, 1963). Se concentraban en las ciudades industriales, especialmente en las fábricas textiles y en los gremios de la construcción. Friedrich Engels describió la horrenda situación de los trabajadores 
irlandeses y argumentó que la inmigración irlandesa era una «causa del deterioro al que está expuesto el trabajador inglés, una causa permanentemente activa que obliga al descenso de toda la clase» (Engels, 1962: 123).

Este ejemplo histórico es importante por varias razones. En primer lugar, demuestra que la diferenciación no tiene que estar basada en un estatus legal discriminatorio, como lo estaba en la esclavitud y con los trabajadores bajo contrato. Una combinación de vulnerabilidad económica y de prejuicio étnico o racial también puede derivar en inequidad. Segundo, muestra que la discriminación en contra de una parte de la clase trabajadora puede contribuir a deteriorar las condiciones del resto. Marx creía que la clase trabajadora se tornaría más homogénea y tendría intereses comunes en la lucha contra el capital, pero la historia de las relaciones laborales muestra una imagen distinta: la diferenciación y la exclusión de ciertos grupos han sido aceptadas con frecuencia por otros, lo que ha llevado al surgimiento de lo que más tarde Lenin llamaría una «aristocracia de la clase trabajadora» (Lenin, 1968). Karl Polanyi argumentaba que un modelo liberal puro basado en la ficción de la libertad contractual para los trabajadores individuales, inevitablemente destruiría las condiciones que hacían posible la industria capitalista, al degradar a los trabajadores hasta el punto en que la fuerza de trabajo futura no podría reproducirse. $\mathrm{El}$ «doble movimiento» de la movilización de la clase trabajadora, el sindicalismo y la legislación para proteger a los trabajadores, en realidad es una precondición para la sobrevivencia del sistema capitalista (Polanyi, 2001). La disposición de los trabajadores privilegiados a aceptar condiciones inferiores para otros — sean los criterios de género, raza, etnia, nacionalidad, estatus legal, orígenes o vulnerabilidad — ha sido, y sigue siendo, un factor crucial de estabilización para el orden capitalista liberal.

Estados Unidos, que recibió a 30 millones de inmigrantes entre 1861 y 1920, es visto, por lo general, como el epítome de la libre migración (Borjas, 1990). De hecho, la inmigración era racialmente selectiva con leyes que mantenían fuera a los asiáticos y a los africanos. Los patrones de asentamiento estaban estrechamente vinculados con la emergente economía industrial. E1 
reclutamiento de fuerza de trabajo por las compañías constructoras de canales y ferrocarriles desembocó en el establecimiento de irlandeses e italianos a lo largo de las rutas de construcción. Algunos grupos de irlandeses, italianos y judíos se establecieron en los puertos de llegada de la costa este, en donde había empleo en la construcción, el transporte y las fábricas. Los inmigrantes chinos se establecieron en un principio en la costa oeste, pero se trasladaron tierra adentro tras el reclutamiento de parte de las compañías de construcción de las vías para el ferrocarril. De igual manera, los primeros migrantes de origen mexicano se concentraron en el suroeste, cerca de la frontera mexicana, pero muchos se trasladaron hacia el norte en respuesta al reclutamiento de los ferrocarriles. Algunos europeos del centro y este del continente se concentraron en el medio oeste, donde el desarrollo de la industria ofrecía oportunidades de empleo (Portes y Rumbaut, 2006: 38-40). De tal forma, la clase trabajadora estadounidense se desarrolló a través de procesos de migración en cadena, lo que llevó a la segmentación étnica. Sin embargo, la diferenciación entre los grupos étnicos blancos ha resultado mucho menos duradera que la división fundamental entre blancos y afroamericanos.

Durante la industrialización, aproximadamente de 1850 a 1914, Alemania, Francia y otros países europeos hicieron un amplio uso de fuerza de trabajo migrante. Los principales factores de diferenciación eran el estatus legal, la etnia y la nacionalidad. Alemania recurrió al uso de trabajadores polacos, utilizando una fuerza policial especial para disciplinarlos, e insistiendo en que salieran del país cada año durante un lapso, para evitar que se establecieran. Francia, en contraste, buscaba convertir a los migrantes en ciudadanos, de modo que pudieran servir como soldados en las guerras que estaban por venir contra Alemania. Después de la Primera Guerra Mundial, Francia reclutó una gran cantidad de trabajadores migrantes provenientes de Italia y Polonia para compensar las pérdidas de la guerra, sólo para tratar de expulsarlos nuevamente cuando fue golpeada por la Gran Depresión en los años treinta. Más tarde, la Alemania nazi reclutó a millones de trabajadores extranjeros — principalmente a la fuerza - para reemplazar a los 11 millones de trabajadores alemanes que 
fueron conscriptos para el servicio militar. Los trabajadores fueron hospedados en barracas con control militar, tenían sueldos muy bajos y condiciones sociales horrendas. Muchos trabajadores extranjeros murieron por el trato rudo y los castigos crueles. Los nazis llevaron al extremo la explotación de los migrantes sin derechos, la que sólo puede compararse con la esclavitud, aunque su médula legal — la marcada división entre el estatus de nacional y de extranjero- habría de encontrarse en los sistemas de trabajo extranjero tanto antiguos como posteriores (Castles y Miller, 2009: 87-93).

\section{Sistemas de trabajadores MigRANTES Y MIGRANTES COLONIALES, I 945-I 974}

Después de 1945, la experiencia de la Gran Depresión y la derrota del nazismo abrieron el camino para nuevas formas de capitalismo de bienestar, fundamentado en el pleno empleo, fuertes movimientos de trabajadores y políticas sociales redistributivas (Esping-Andersen, 1990; Schierup et al., 2006). La inequidad se redujo en muchos países mientras que la situación de los trabajadores mejoró. Los gobiernos de los Estados capitalistas centrales en Europa occidental y Estados Unidos promovían la inmigración para contar con fuerza de trabajo en los empleos que rechazaban los trabajadores locales y para reducir la presión al aumento de salarios. Estados Unidos impulsaba una política de inmigración selectiva en términos raciales, principalmente proveniente de Europa hasta 1965, mientras reclutaba trabajadores procedentes de México para cubrir los empleos que requerían escasa calificación en la agricultura y, cada vez más, en la construcción y la manufactura. Las modificaciones al Acta de Inmigración y Nacionalidad (Immigration and Nationality Act) en 1965 derivaron en un nuevo sistema de inmigración proveniente de todo el planeta. Sin embargo, por razones de espacio, aquí no discutiremos más este tema. Me centraré en la migración hacia Europa occidental, que fue de dos tipos principales (Castles y Kosack, 1973). 
Primero, prácticamente todos los países del oeste de Europa empleaban a trabajadores extranjeros, muchos de los cuales eran reclutados por los gobiernos o los patrones como fuerza de trabajo temporal (o «trabajadores huéspedes»). Algunos países como Francia, Gran Bretaña y Suecia estaban relativamente abiertos a la reunificación familiar y a las estancias de largo plazo. Otros, como la República Federal de Alemania, Austria y Suiza, se esforzaban por evitar el establecimiento por medio de la «rotación» de trabajadores, es decir, una circulación constante de migrantes a corto plazo. Alemania estableció el más sofisticado sistema de trabajadores huéspedes, con un alto grado de control estatal sobre el reclutamiento, condiciones laborales y derechos de los migrantes. El sur de Europa, el norte de África, Turquía, Finlandia e Irlanda ofrecieron reservas de fuerza de trabajo a los países industriales centrales, mientras que los países de Europa del este y central, miembros del bloque soviético, impusieron rígidas restricciones para salida de personas.

Segundo, los poderes imperiales usaban la fuerza de trabajo proveniente de las antiguas colonias o las existentes: el Caribe y el subcontinente indio para Gran Bretaña, el norte y el oeste de África para Francia y el Caribe e Indonesia para Holanda. Por lo general, no existía un reclutamiento oficial: el conocimiento de las oportunidades de empleo en las antiguas metrópolis, junto con el derecho legal a ingresar, era suficiente para comenzar las cadenas migratorias. En el periodo colonial ciertos pueblos colonizados habían recibido la ciudadanía (o, en el caso británico, el estatus de «súbditos» de la corona) como una forma de integración ideológica. Esto facilitaba entonces el ingreso de una fuerza de trabajo muy necesaria, pero también significaba que los trabajadores coloniales podrían llevar consigo a sus dependientes económicos y establecerse.

En estas prácticas de reclutamiento de fuerza de trabajo podemos ver diversos modos de diferenciación. Los países que importaban trabajadores huéspedes usaban la distinción entre nacionales y extranjeros como el mecanismo clave para controlar la fuerza de trabajo migrante e imponer derechos inferiores. En algunos países - especialmente en los primeros años de reclutamiento- los trabajadores estaban ligados a un patrón y a una ocupación 
específicos, tenían derechos limitados a la seguridad, no se les permitía llevar a sus dependientes y podían ser deportados si incumplían las condiciones de sus contratos. Eran estos poderosos instrumentos disciplinarios los que obligaban a los migrantes - incluso a quienes contaban con educación y capacitación-a aceptar empleos de escasa calificación, bajos sueldos y condiciones inferiores.

En contraste, los migrantes coloniales por lo general contaban con la ciudadanía en el país de inmigración y tenían derechos residenciales y laborales plenos. Aquí el mecanismo de diferenciación era el racismo: las culturas del racismo fundamentadas en siglos de colonialismo eran formas efectivas de asegurar que los migrantes entraran a los mercados de trabajo en niveles bajos y encontraban muy difícil asegurar la promoción. Una posición desventajosa en el mercado laboral con frecuencia derivaba en segregación en barrios pobres con servicios inadecuados y con instalaciones educativas por debajo de la normatividad.

La diferenciación por estatus nacional y por discriminación racial tenía el mismo efecto de crear un estrato inferior en desventaja dentro de la clase trabajadora. Por supuesto que la distinción no era rígida. Los trabajadores extranjeros y sus familias en Europa occidental experimentaban racismo o xenofobia, al tiempo que los antiguos poderes imperiales pronto comenzaron a despojar a los súbditos coloniales de su estatus de ciudadanos. Para los años sesenta, a la luz del declive económico y los crecientes problemas en las relaciones comunitarias, las autoridades de los tres antiguos poderes coloniales comenzaron a introducir leyes restrictivas (como la de Gran Bretaña con el decreto sobre los inmigrantes a la comunidad de 1962, Commonwealth Immigrants $A c t)$ para detener la inmigración desde las antiguas colonias. A partir de entonces hubo una convergencia en el estatus entre los trabajadores huéspedes y los inmigrantes provenientes de las antiguas colonias.

Desde que comenzó el reclutamiento a mediados de los años cincuenta, las autoridades y los patronos de origen alemán denominaban a los trabajadores huéspedes Konjunkturpuffer, es decir, un escudo en contra de las fluctuaciones económicas. La idea era que los migrantes formaban un «ejército 
industrial de reserva» (cfr. Marx, 1976: 781-794) que ingresaba cuando se necesitaba fuerza de trabajo y salía del país en caso de recesión. A diferencia de los trabajadores huéspedes, los migrantes coloniales no tenían un estatus legal desventajoso, pero la discriminación racial y la exclusión social tenían efectos similares: los trabajadores no europeos en Gran Bretaña, Francia y Holanda se concentraban en las industrias vulnerables ante las debacles y tenían altas tasas de desempleo. La recesión de mediados de los años setenta habría de mostrar si la estrategia del Konjunkturpuffer podría funcionar en el largo plazo.

\section{LAS NUEVAS MINORÍAS ÉTNICAS Y \\ LA DESINDUSTRIALIZACIÓN}

La «crisis petrolera» de 1973 precipitó una reorientación. Todos los países del norte y oeste de Europa que importaban fuerza de trabajo detuvieron el reclutamiento en 1974, excepto Gran Bretaña, que lo había hecho previamente. Parecía que había terminado la inmigración a gran escala hacia Europa occidental y los gobiernos esperaban que los trabajadores huéspedes partieran - una forma cómoda de exportar el desempleo-. Muchos trabajadores migrantes se fueron, pero estos provenían de países como España, Portugal y Grecia, que pronto ingresarían a la Comunidad Europea. Aquellos provenientes de países de origen pobres como Turquía, Argelia y Marruecos, tendían a quedarse. Pronto, otro tipo de inmigración se tornó importante: la reunificación familiar, el ingreso de los cónyuges, hijos y otros parientes de los primeros migrantes. El predominio de los hombres jóvenes se diluyó, se formaron nuevas familias y los inmigrantes originales envejecieron. La conciencia de muchos inmigrantes se transformó de ser visitantes temporales a residentes permanentes. Se establecieron asociaciones sociales, culturales y políticas y surgieron negocios y servicios étnicos.

Desde principios de los años ochenta se volvió prominente otra nueva forma de inmigración: el flujo de llegada de los solicitantes de asilo. El dar la 
bienvenida a los refugiados del levantamiento húngaro de 1956 o de la primavera de Praga de 1968 había constituido un golpe de propaganda a favor de occidente, con un amplio apoyo del público. Pero ahora la mayor parte de los solicitantes de asilo provenían de América Latina, Asia y África, y era frecuente que estos huyeran de las guerras derivadas del conflicto este-oeste, en donde la Europa oficial con frecuencia se ponía del lado de los regímenes autoritarios. A principios de los años noventa, el fin de la Guerra Fría y los conflictos en la antigua Yugoslavia derivaron en flujos masivos de solicitantes de asilo, especialmente hacia Alemania, país que en 1992 recibió más de 400 mil solicitudes de asilo. Los temores populares de flujos masivos provenientes del este y el sur derivaron en una politización del asilo y de la inmigración.

Los gobiernos centrales fueron lentos para aceptar la realidad de los nuevos tipos de inmigración, establecimiento y surgimiento de nuevas minorías. Tanto el gobierno alemán como el francés intentaron limitar los flujos de ingreso de los cónyuges e hijos de los migrantes, pero se vieron forzados a abandonar esos esfuerzos: pronto se vio que las constituciones y sistemas legales de los países democráticos eran un poderoso antídoto frente a los intentos de los gobiernos por restringir los derechos de los migrantes. Además, los trabajadores migrantes habían obtenido derechos dentro de los Estados de bienestar europeos: aun en caso de desempleo, muchos estaban mejor si permanecían en Europa, en lugar de regresar a sus países pobres.

Esta experiencia mostró las limitaciones del principio del Konjunkturpuffer. Como señaló Tomas Hammar, muchos migrantes se habían convertido en denizens: aunque no habían logrado el estatus legal de ciudadanos, habían adquirido muchos derechos civiles y sociales a partir de la residencia a largo plazo (Hammar, 1990). No podían ser enviados simplemente fuera del país en un momento de recesión. Por otra parte, los trabajadores migrantes (ya fueran antiguos trabajadores huéspedes o migrantes coloniales) perdían sus puestos de trabajo con mayor frecuencia que los trabajadores nativos y tenían tasas de desempleo más altas y mayores desventajas sociales. Esto era muy visible en Gran Bretaña, en donde los trabajadores indios, paquistaníes 
y bangladesíes, reclutados en los años cincuenta y principios de los sesenta para las industrias textiles y del vestido de Yorkshire y Lancashire, soportaban la carga de la desindustrialización. Los viejos pueblos molineros como Bradford y Oldham se convirtieron en tierras improductivas de desempleo y decadencia social, en donde sus habitantes carecían de los recursos para trasladarse a otros lugares. Esos pueblos serían el centro de los enfrentamientos entre asiáticos y blancos en 2001.

En toda Europa occidental y Estados Unidos los migrantes y las minorías étnicas se encontraban entre los grupos más afectados por la desindustrialización. La inmigración resultó no ser el Konjunkturpuffer de gran alcance que se había vislumbrado originalmente, pero sí amortiguó parcialmente a los grupos mayoritarios en contra del desempleo. La exclusión de la ciudadanía plena y el racismo resultaron ser poderosos factores para legitimar la división de los grupos en desventaja entre los pobres «con merecimientos» y los que «no merecían» (Schierup y Castles, 2011).

Aun cuando los sindicatos y los grupos de la sociedad civil iniciaron luchas - frecuentemente con algún éxito- en contra de la discriminación, la incorporación inicial en los niveles más bajos del mercado laboral generó una dependencia de la trayectoria, haciendo muy difícil para los migrantes y sus hijos lograr una movilidad ascendente. Los migrantes y los miembros de las minorías desarrollaron una gama de estrategias individuales para superar esta situación, incluyendo el establecimiento de pequeñas empresas y la búsqueda del logro educativo. La pregunta es si esas estrategias podrían ser suficientes para superar los enquistados mecanismos de diferenciación.

\section{El NeOLIBERALISMO Y}

\section{EL NUEVO MERCADO GLOBAL DE TRABAJO}

La recesión de mediados de los años setenta constituyó un importante punto de inflexión, marcando el fin del sistema fordista de producción en masa en 
los viejos países industriales. El reclutamiento de fuerza de trabajo migrante fue reemplazado por flujos de salida del capital hacia nuevas áreas industriales en el Sur global. Estos, a su vez, precipitaron grandes flujos de trabajadores, por ejemplo del sur de Asia hacia los países petroleros del Golfo y, con cierto rezago, desde partes menos desarrolladas de Asia hacia los nuevos tigres industriales.

Entre mediados de los años setenta y el inicio de la CEg en 2008, se desarrolló un nuevo mercado global de trabajo con base en ideas neoliberales. Sus principios fueron sintetizados en el «Consenso de Washington» de fronteras abiertas, mercados libres, un Estado pequeño y desregulación. Los defensores de la globalización neoliberal proponen el argumento legitimador de que esos principios llevarán a un crecimiento económico más rápido en los países pobres y, de esa forma, en el largo plazo, a la reducción de la pobreza y a la convergencia con los países más ricos. De hecho, ha ocurrido lo contrario: según un economista del Banco Mundial, la inequidad global para mediados de la década de 2000 fue «probablemente la más alta registrada en la historia» (Milanovic, 2007: 39).

Los gobiernos de los antiguos países industriales esperaban que la exportación de las unidades manufactureras (outsourcing) y el traslado a una economía postindustrial eliminaran la necesidad de inmigración de fuerza de trabajo. El nuevo énfasis en Estados Unidos, Canadá, Australia y Europa occidental se daba en facilitar el ingreso de personal altamente capacitado y de empresarios. Para los trabajadores manuales había una «política de inmigración cero». A principios del siglo XXI, nuevos países industriales como Corea del Sur, Hong Kong, Singapur e incluso China se unían a la competencia global para atraer talentos. Pero la idea de que no se necesitarían trabajadores de escasa capacitación estaba bastante equivocada. Como señalara Saskia Sassen (1988), las economías postindustriales de servicios necesitaban grandes cantidades de trabajadores de escasa capacitación para atender las necesidades de las élites: trabajadores de la construcción, jardineros, trabajadores de la alimentación, trabajadores domésticos, personal de cuidados personales, 
limpiadores y demás. Esos trabajadores no podían conseguirse en las fuerzas laborales locales, primero por razones demográficas, ya que descendió la fecundidad y descendieron las cifras de personas jóvenes que ingresaban a los mercados laborales en los países ricos, y segundo, por razones sociales, dado que los jóvenes locales tenían buenas oportunidades educativas y rechazaban el trabajo de escasa capacitación. Dado que los gobiernos permanecían indispuestos a admitir la necesidad vigente de trabajadores migrantes de escasa capacitación, estos eran reclutados (hasta la CEG) ya fuera por medio de esquemas especiales de trabajo temporal (como en Alemania), ya fuera por la movilidad dentro de la Unión Europea (UE) — Gran Bretaña e Irlanda-, ya fuera por medio de la migración irregular (Estados Unidos, sur de Europa y varios países asiáticos) (Castles et al., 2012).

Al utilizar nuevas tecnologías de transporte y control se tornó posible dividir y desplazar fuera del país (outsourcing) las distintas etapas de la producción y así construir cadenas globales de producción, al tiempo que se conservaba el control y las ganancias dentro de las corporaciones multinacionales, todavía con sede, en gran medida, en Estados Unidos y en otros países altamente desarrollados. Al mismo tiempo, los economistas argumentan que el retiro de las restricciones a la movilidad humana podría derivar en grandes incrementos en el ingreso global (Bhagwati, 2003; Nayar, 1994). Así como los teóricos liberales en el siglo xIx, los neoliberales presentan la economía mundial como basada en el libre mercado, donde los patronos y los trabajadores se encuentran como sujetos legales libres, con derechos iguales para establecer contratos. La migración internacional se plantea como un mercado en el cual los trabajadores pueden decidir libremente trasladarse al área donde recibirán el ingreso más alto ( $c f r$. Borjas, 1990: 9-18).

Pero esta imagen de armonía con frecuencia se aleja de la realidad. Los políticos en los países que importan fuerza de trabajo están conscientes de la hostilidad popular a la inmigración y han respondido con una retórica de soberanía nacional y control. Este interjuego entre las fuerzas del mercado que exigen libertad y las fuerzas políticas que exigen control es altamente efectiva 
para generar un mercado global de trabajo que está diferenciado no sólo según el «capital humano» (posesión de educación, capacitación y habilidades laborales), sino también de acuerdo con el género, raza, etnia, origen y estatus legal. Es importante comprender las formas cruciales de diferenciación de la fuerza de trabajo en el actual mercado global de trabajo. Algunas son relativamente nuevas, mientras que otras tienen una larga historia, aunque con nuevos aspectos.

\section{Nuevas formas de empleo: subcontratación, trabajo temporal informalidad}

Un nuevo elemento en las prácticas neoliberal de empleo ha sido la tendencia de convertir a los trabajadores asalariados, que gozan de la protección de la ley laboral y contratos colectivos, en «contratistas» independientes, que no tienen garantía de empleo y ahora tienen que comprar su propia herramienta y equipo, además de soportar todos los riesgos de accidentes, enfermedades o desempleo (Schierup et al., 2006: capítulo 9). La presión para convertirse en contratistas independientes ha afectado a ocupaciones tan diversas como las de los gremios de constructores, conductores de camiones, diseñadores gráficos y arquitectos.

Emplear migrantes temporalmente es otra forma de aumentar el control patronal y reducir la demanda de mejores salarios y condiciones de trabajo. En 2007, la ocDE encontró que los migrantes tendían más a estar empleados en puestos temporales en comparación con los nativos en casi todos los países europeos de inmigración. En España, 56\% de los nacidos en el extranjero tenía empleos temporales, en comparación con menos de 30\% de los locales (ocDE, 2007: 75-76) —lo que puede ayudar a explicar el rápido aumento en el desempleo de los migrantes en España durante la CEG-. En la parcial recuperación económica de Europa en 2010, los trabajadores migrantes estaban sobrerrepresentados en las nuevas contrataciones, principalmente debido a un cambio en los contratos temporales (ocDE, 2011: 86).

244 MIGRACIÓN Y DESARROLLO, VOL. 11, NÚM. 20, PRIMER SEMESTRE DE 2013 
La desregulación económica ha derivado en la remoción de los controles legales en el empleo y en la reducción de las inspecciones de los lugares de trabajo por las autoridades del mercado de trabajo. Esto permitió una gran expansión en la contratación por hora o a destajo, en especial para los migrantes, jóvenes y mujeres. Los trabajos informales son típicos en limpieza, alimentación y otras ocupaciones de servicio, pero también en industrias de la construcción, textil y de vestir. Muchas grandes corporaciones ya no participan directamente en la producción, sino que subcontratan a empresas más pequeñas. Por medio de la subcontratación persiguen un máximo de flexibilidad. La frecuente alabanza al aumento del «empresariado étnico» debe verse en el contexto de esta tendencia.

\section{Trabajadoras migrantes}

La diferenciación basada en el género sigue siendo tan importante como siempre. A medida que la demanda de fuerza de trabajo masculina ha decaído debido a los descensos en el empleo en la manufactura y la construcción, las mujeres han tenido que soportar una carga creciente. Los nuevos sectores en crecimiento (como el trabajo doméstico y el cuidado de personas) están ligados con los papeles femeninos tradicionales, y la informalización de ese trabajo ha arrastrado a la baja el pago y las condiciones laborales, derivando en «un nuevo crecimiento en las inequidades y las inseguridades» (Piper, 2011: 65).

Antes de la CEG, la OCDE encontró que «las mujeres inmigrantes por lo general son el grupo con los resultados menos favorables en el mercado laboral [...], tanto en términos absolutos como en relación con los hijos de los nativos del mismo género» (ocDE, 2007: 81-82). Como se señaló antes, las mujeres migrantes se vieron menos afectadas que los hombres por el desempleo durante la CEG, debido a su concentración en los sectores menos afectados por la caída. Sin embargo, tuvieron que compensar las pérdidas en el ingreso familiar cuando los hombres perdieron sus empleos (OCDE, 2011). 
Dado que las mujeres tienen niveles de paga sustancialmente más bajos que los hombres, esto representó un incremento en la carga de trabajo de las mujeres, más que un paso hacia la equidad de género. Un estudio en Estados Unidos reveló que «las mujeres de color están situadas diferencialmente en los mercados locales de trabajo en comparación con las mujeres blancas y los hombres del mismo grupo étnico, de modo que la reestructuración económica afecta de manera única a cada grupo» (Browne y Misra, 2003: 497).

Las mujeres migrantes que realizan trabajo doméstico constituyen una categoría de fuerza de trabajo dividida por género y raza que se ha expandido de manera notable a prácticamente todas las economías industriales avanzadas (Anderson, 2000, 2007; Cox, 2006). El trabajo doméstico está marcado por una jerarquía de tareas en el trabajo, modos formales e informales de empleo y grupos con estatus diversos. Por ejemplo, se prefiere a las trabajadoras domésticas filipinas en algunos lugares debido a su mejor educación y su manejo del idioma inglés, pero son rechazadas en otros porque se les ve demasiado activas en la defensa de sus derechos. El trabajo doméstico de las mujeres migrantes puede ser la consecuencia de un aumento en las oportunidades de empleo profesional o burocrático para las mujeres del grupo mayoritario: contratar a sirvientas extranjeras puede liberar a las mujeres en Italia, Estados Unidos o Singapur del trabajo en casa y del cuidado de los niños (Huang et al., 2012; Huang et al., 2005). Esas jerarquías transnacionales en el cuidado de otras personas a veces van una etapa más adelante, cuando las trabajadoras domésticas migrantes contratan una sirvienta en el país de origen para que cuide de sus hijos. Las «cadenas globales de cuidado de personas» pueden significar estándares superiores de vida y mejor educación, pero a un alto costo afectivo.

\section{El crecimiento de la economia informal}

Una de las más marcadas tendencias de los últimos 30 años ha sido el crecimiento de las economías informales en los países industriales avanzados. En 
el pasado, las prácticas de empleo informal estaban asociadas con los países menos desarrollados, en donde la falta de empleo regular obligaba a la gente a buscar su sostén a través de la producción artesanal y el comercio en pequeño. El neoliberalismo y la desregulación económica han llevado a un florecimiento del trabajo informal en los mercados de trabajo que antes estuvieron altamente regulados. Todas las tendencias mencionadas - subcontratación, trabajo temporal, informalidad y situaciones de división del trabajo por género y razapueden sintetizarse por medio del concepto de informalización, es decir, «una redistribución del trabajo de los sectores regulados de la economía a nuevos sectores no regulados de la economía clandestina o informal» (Ness, 2005: 22).

Aunque el empleo informal puede afectar igualmente a los nativos y a los inmigrantes, la migración irregular ha sido crucial para su crecimiento. Esto es particularmente obvio en Estados Unidos, con una población irregular que se estima en cerca de 11 millones (Passel y Cohn, 2011). La mayor parte de ellos son migrantes mexicanos y otros centroamericanos y caribeños en empleos de escasa capacitación. En Europa, los cálculos más confiables en cuanto a la cifra de residentes irregulares en la uE15 (los países de la UE antes de las ampliaciones de 2004 y 2007) iban de los 1.8 a los 3.3 millones en 2008 (Clandestino, 2009: tabla 1). Algunos políticos argumentan que la inmigración irregular es la causa de la informalización, pero la investigación muestra que la informalidad se da de forma inversa: la desregulación económica y las prácticas de los patrones han generado empleos en el sector informal, generando un factor de atracción para los migrantes irregulares (Reyneri, 2003). El empleo informal constituye una parte crucial de la nueva economía global, como señala Immanuel Ness: «[...] la informalización no representa decadencia industrial sino una reestructuración horizontal, que con frecuencia se realiza para conservar e incrementar la flexibilidad y la competitividad en los mercados regional, nacional e internacional» (Ness, 2005: 23). 


\section{De la segmentación del}

mercado laboral al empleo precario

En conjunto, las diversas formas de reestructuración de la fuerza de trabajo se suman a un proceso llamado por los economistas segmentación del mercado laboral. Esto significa que las posibilidades de que la gente obtenga empleo dependen no sólo de su capital humano, sino también de su género, raza, etnia, estatus legal, edad, ubicación y otros criterios no económicos. Más recientemente, los científicos sociales han comenzado a hablar de trabajo precario y a analizar los procesos que empujan a ciertas categorías de trabajadores - especialmente a los migrantes - hacia empleos inseguros y explotadores. Guy Standing argumenta que el precariado emergente constituye una nueva categoría socioeconómica de importancia global (Standing, 2011). Queda claro que es importante comprender la relación entre los trabajadores precarios y la más amplia jerarquía de clase.

La segmentación del mercado de trabajo no es nueva. La migración laboral hacia Europa occidental, Australia y Estados Unidos después de la guerra derivó en segmentación, fragmentación de clase y nuevas formas de estratificación social y económica (Castles y Kosack, 1973; Collins, 1991; us Department of Labor, 1989). Sin embargo, la segmentación del mercado de trabajo está cambiando de maneras complejas, vinculada a una nueva geografía social global. En los años ochenta, Saskia Sassen (1988) mostró cómo la inversión extranjera y el desplazamiento de los trabajos en la manufactura hacia el extranjero habían generado nuevos flujos migratorios hacia Estados Unidos. Los vínculos entre las ciudades globales y las distantes hinterlands generaron una situación en la cual el empleo profesional altamente remunerado coexistía incómodamente con el creciente empleo en la industria del servicio no calificado y las condiciones de empleo del tercer mundo en las industrias clandestinas. Era frecuente que coincidiera un considerable empleo ilegal de los migrantes con un alto desempleo de los ciudadanos y de 
los extranjeros que residían legalmente. Estos últimos tenían una alta probabilidad de pertenecer a minorías y con frecuencia habían sido víctimas de la pérdida del empleo en las industrias que habían trasladado sus operaciones de manufactura hacia el extranjero.

Veinte años después, Immanuel Ness analizó la transformación de la geografía social de la ciudad de Nueva York City (Ness, 2005: capítulo 2). A principios del siglo $\mathrm{xx}$, la fuerza de trabajo inmigrante proveniente del sur y del este de Europa había sido crucial para el surgimiento de las industrias del vestido, imprenta, procesamiento de carne, construcción y transporte. La industria se concentraba en «barrios étnicos» y los inmigrantes provenían del corazón del poderoso movimiento de trabajadores de la ciudad. A fines del siglo $\mathrm{xx}$, estas industrias tradicionales fueron reestructuradas y la mayor parte de los empleos productivos se habían trasladado a los estados del suroeste de Estados Unidos, en donde no había sindicatos, o hacia el extranjero, al Caribe, América Latina y Asia. Se crearon nuevos empleos en la venta al menudeo, servicios personales y servicios a las empresas, y la nueva economía estaba fuertemente estratificada con base en la pertenencia étnica.

Pueden encontrarse paralelos en otras partes. Tras la reunificación alemana en 1990, Berlín experimentó un explosivo crecimiento, sin precedentes, en la construcción. No obstante, para 1996, 25\% de las personas sin empleo en Berlín eran trabajadores de la construcción. Algunos patrones tomaron trabajadores provenientes de Polonia, quienes llegaron mediante esquemas de trabajo temporal. Otra opción era subcontratar trabajo a las firmas portuguesas, que podrían traer a sus propios trabajadores (con salarios más bajos) por medio de las provisiones de libre tránsito de la UE. Otros trabajadores se trasladaban diariamente desde Brandenburgo, que fue parte de Alemania del Este. Esta competencia tuvo efectos adversos en los trabajadores de la construcción sindicalizados, muchos de los cuales eran residentes extranjeros establecidos en Berlín. En el viejo modelo alemán de empleo a largo plazo, la empresa y el sindicato habían sido espacios de comunicación e integración interétnicas. La decadencia de este modelo y su reemplazo por trabajadores 
contratados tuvo efectos negativos en la integración social y en las relaciones entre grupos. Éste fue un factor subyacente en el incremento del racismo y la violencia racista tras la reunificación alemana (Hunger y Thränhardt, 2001).

La industria del vestido ofrece muchos ejemplos de jerarquías con base en la raza y el género (Rath, 2002). En Gran Bretaña, las divisiones étnicas y de género permitieron el reavivamiento de la producción de ropa luego de que pareciera estar condenada a la extinción por la maquila que se solicitaba en las economías de bajos sueldos (véase Phizacklea, 1990). Desde los años setenta, la administración, el diseño y la comercialización de ropa se había concentrado fuertemente en unas cuantas compañías británicas altamente capitalizadas de venta de ropa al menudeo. Durante los años sesenta y setenta, la fuerza de trabajo inmigrante en la industria del vestido había estado poblada por inmigrantes varones de primera generación: paquistaníes, indios, bangladesíes y otros. Muchos de estos trabajadores perdieron sus empleos y luego se convirtieron en contratistas de las grandes casas de ropa, estableciendo talleres pequeños formalmente independientes que se sostenían con base en la fuerza de trabajo de las minorías étnicas o de las familias de inmigrantes. La informalidad de la industria se adaptaba tanto a los intereses económicos de los grandes vendedores al menudeo, como a los propios de los varones étnicos que servían de intermediarios, quienes controlaban a su fuerza de trabajo, consistente principalmente en fuerza de trabajo femenina mediante lazos de lealtad a la familia y a la comunidad étnica (Schierup et al., 2006: 235-237).

La expresión trabajo precario se utiliza cada vez más para caracterizar la reestructuración neoliberal de los mercados de trabajo. Standing (2011: 90) señala que «los migrantes constituyen una gran parte del precariado mundial». La investigación comparativa reciente en Europa revela «las penalidades del mercado de trabajo de los nuevos inmigrantes» y muestra cómo éstas se ligan a una gama de factores, incluyendo el estatus legal a la llegada, los efectos de los procesos de regularización, los diferentes tipos de demanda de fuerza de trabajo en varios países y el intercambio entre desempleo y reducción en la capacitación (Reyneri y Fullin, 2010). 
Un estudio sobre el mercado laboral en Toronto de Goldring y Landolt (2011) vincula el estatus laboral y los derechos de ciudadanía mediante una «matriz de trabajo-ciudadanía». Esta valiosa herramienta para la investigación empírica enumera los indicadores del trabajo precario, como el nivel de sindicalización, tipo de contrato, términos de empleo y pago en efectivo, y propone una escala de tres pasos para cada indicador. El nivel de precariedad puede luego asociarse mediante un análisis de regresión a una gama de factores explicativos con base en el capital individual y humano, los hogares y las redes, los factores contextuales y de política y las condiciones macroeconómicas y del mercado de trabajo. Goldring y Landolt encontraron que una transición del estatus irregular al legal no llevaba a resultados significativamente mejores en el mercado de trabajo. Los mercados de trabajo se estaban estratificando según el estatus migratorios y el estatus precario se convertía en «una fuente de vulnerabilidad en el corto plazo, así como una trampa en el largo plazo porque los empleos de bajos sueldos y precarios se convertían en una red "pegajosa" para la gente con un estatus precario» (Goldring y Landolt, 2011).

\section{LA CRISIS ECONÓMICA GLOBAL}

¿De qué manera la ceg ha afectado al mercado global de trabajo y a los patrones de diferenciación por los cuales está estructurado? Todavía es demasiado pronto para una respuesta completa y, en cualquier caso, no hay ni tiempo ni espacio aquí para ella. En cambio, me enfocaré en las tres incógnitas que planteé al comienzo de este artículo.

1. El desempleo de los trabajadores nacidos en el extranjero en los países de la oCDE se incrementó a un ritmo doblemente rápido en 2008-2009 en comparación con el de los nacidos en esos países. Pero el empleo de los nacidos en el extranjero se incrementó en 5\% en 2008-2010, 
mientras que el empleo de los nacidos en esos países se redujo en 2.2\% (ocDE, 2011: 74-5). ¿Cómo podemos explicar el incremento simultáneo en el empleo y en el desempleo de los nacidos en el extranjero? ¿Qué significa?

En Europa occidental (la UE15), la tasa promedio de desempleo de los nacidos en el extranjeros se incrementó en 3.4 puntos porcentuales entre 2008 y 2009, el doble que para los nacidos en esos países. El mayor incremento se dio en Irlanda (ocho puntos porcentuales) y en España (11 puntos porcentuales). En Estados Unidos, la tasa de desempleo para los inmigrantes superó el doble de puntos porcentuales, de $4.3 \%$ a 9.7\%. La crisis estuvo marcada por agudas caídas en la construcción, manufactura, finanzas y comercio al mayoreo y menudeo. Los inmigrantes estaban sobrerrepresentados en estos sectores, lo que constituye una razón por la cual fueron más afectados por la crisis. Esto demuestra la importancia de la dependencia de la trayectoria discutida previamente: debido a que los trabajadores migrantes se incorporan principalmente en ciertas ocupaciones e industrias, fueron golpeados más duramente cuando decayeron los «empleos de la franja oxidada». No obstante, el empleo de los extranjeros en los países europeos de la OCDE de hecho se incrementó en 5\% desde principios de 2008 hasta el tercer trimestre de 2010, mientras que se redujo el empleo de los nacidos en el país en 2.2\% (ocDE, 2011: 74-75). Ello fue consecuencia de los factores ya mencionados: transformaciones demográficas que derivaron en una caída del ingreso de los jóvenes en la fuerza laboral y transformaciones como mejores oportunidades educativas para los locales. El incremento en el empleo de los migrantes, por ende, continuó, aun durante la CEG.

2. Los hombres migrantes dentro de los países de la ocDE fueron afectados mucho más por el desempleo que las mujeres migrantes. Éstas incrementaron su participación en la fuerza laboral y tuvieron menores tasas de desempleo (ocDE, 2011: 78-81). ¿Por qué fue eso? ¿Refleja 
ello un mejoramiento de la posición de las mujeres migrantes en el mercado de trabajo?

Esto sucedió principalmente porque los hombres migrantes tendían a estar empleados en los sectores más duramente golpeados por el declive, en especial en la manufactura y la construcción, mientras que las mujeres migrantes estaban más concentradas en sectores menos afectados, de manera notable en los servicios sociales, cuidado de otros y trabajo doméstico. Al mismo tiempo, la CEG reforzó la tendencia hacia el empleo de tiempo parcial, temporal e informal, mientras que las mujeres tendían más a entrar a esas relaciones de empleo que los hombres (ocDE, 2011: 78-81). De modo que el desempleo relativamente más bajo que el de los hombres no ha significado una mejor situación para las mujeres migrantes; en cambio es frecuente que se les empuje a empleos precarios y se les obligue a trabajar durante horarios más prolongados que antes para lograr que su ingreso sea suficiente.

Otro inquietante efecto de la CEG en los países europeos de la OCDE ha sido el de tasas mucho más altas de desempleo entre los jóvenes migrantes que para los jóvenes nativos. El desempleo a largo plazo también constituyó un problema de importancia: más de la mitad de todos los migrantes desempleados habían carecido de empleo por más de un año en Alemania, mientras que la cifra en otros países era de 30\% o más (ocDe, 2011: 85). Las tasas de desempleo variaron según área de origen, siendo los africanos los más afectados.

3. En conjunto, la CEG afectó a las antiguas economías industriales - de forma notable a los países de la OCDE más que a los emergentes en Asia y América latina (Phillips, 2011). ¿Significa eso una transformación en los patrones globales de migración?

A medida que surgen nuevas potencias económicas — como los países BRICS - los patrones de trabajo y migración parecen estar cambiando. La CEG alteró los patrones migratorios en todo el mundo por algún tiempo, pero esos 
efectos fueron más severos y de mayor duración en Europa occidental y en Estados Unidos que en otros lugares. Los patrones globales en todas partes se ven afectados por factores locales específicos. Por ejemplo, el flujo de salidas de México hacia Estados Unidos se redujo de 369 mil en 2006 a tan sólo 114 mil en 2009 (Alba, 2010). A pesar del vacilante regreso al crecimiento en 2010-2011, los flujos de ingreso de los migrantes de escasa calificación permanecieron estancados y la inmigración de mexicanos no mostró signos de recuperación en 2010-2011 (Passel y Cohn, 2011). En América Latina, la imagen es ambigua. En vista del relativo estancamiento de la demanda de fuerza de trabajo en Estados Unidos, los flujos migratorios hacia el norte se han reducido en gran medida. La emigración hacia España desde Ecuador y otros países latinoamericanos y hacia Japón desde Brasil y Perú también se ha reducido y se ha dado una significativa migración de retorno. Sin embargo, el crecimiento económico desigual y el surgimiento de nuevos polos de migración (como Brasil, Chile y Argentina) dentro de América Latina han desembocado en un crecimiento de la movilidad dentro del continente.

A inicios de 2009, el declive económico estaba causando que algunos gobiernos en el sureste y este de Asia cerraran sus fronteras a nuevos trabajadores migrantes. Pero pronto quedó claro que los efectos de la CEG en la migración asiática eran moderados y a corto plazo (IOM, 2011: 68). Las salidas de migrantes desde Bangladesh, que habían decaído en 20\% en 2010, aumentaron en 37\% en los primeros tres trimestres de 2011. Los flujos de salida de trabajadores migrantes desde Filipinas crecieron en 20\% en 2008-2010 y en otro $7 \%$ en los tres primeros trimestres de 2011. Este crecimiento se debió a la demanda de fuerza de trabajo en los países del Consejo de Cooperación en el Golfo (Gulf Cooperation Council [GCC]) al igual que en Rusia, que estaba ligada al alto precio del petróleo. El reclutamiento de marinos filipinos, que surcan los mares bajo distintas banderas, también se incrementó (Mohapatra et al., 2011).

La alta demanda de fuerza de trabajo en los países productores de petróleo revirtió la tendencia de 2008-2009, cuando algunas de esas economías —de manera destacada Dubai- estuvieron en problemas. De igual manera, 
en 2008-2009 se habían dado marcadas caídas en la migración dentro de la Confederación de Estados Independientes. Antes de la crisis, la migración desempeñaba un papel importante, ya que entre 10\% y 25\% de la población de muchos de los países de la cei vivía fuera de ellos. Rusia constituía un polo de atracción primordial, en especial para los trabajadores provenientes de estados del Asia central como Tajikistan y Kazajstán (Canagarajah y Kholmatov, 2010). Pero en 2011, los flujos se recuperaron considerablemente, a medida que se incrementaba nuevamente la demanda de fuerza de trabajo en Rusia y en otros países de destino.

La migración irregular resultó ser particularmente sensible a la demanda del mercado de fuerza de trabajo en los países de destino tan distintos como Estados Unidos, España, los Estados del Golfo y Malasia. Varios gobiernos asiáticos hicieron más rígidos sus controles de ingreso (Abella y Ducanes, 2009). Dado que los migrantes irregulares tienden a basarse en la información y el apoyo de las redes de migrantes anteriores, los migrantes potenciales se enteran pronto de la falta de oportunidades de empleo en las recesiones. Además, los migrantes irregulares, por lo general, carecen del derecho a apoyo de bienestar y tiene escasa motivación para ir a un país de destino o a quedarse en él cuando no hay empleos disponibles.

Un importante efecto emergente de la CEG es el crecimiento de la migración desde las áreas peor impactadas de Europa hacia lugares que todavía ofrecen empleos y oportunidades. A principios de 2012 había reportes de griegos, italianos e irlandeses que se trasladaban a Australia; portugueses que buscaban fortuna en Brasil y Angola, y españoles, italianos y británicos que probaban suerte en Argentina (Smith, 2012). Esos migrantes estaban retomando caminos que se establecieron hace $50 \mathrm{o}$, incluso, hace 100 años, con la diferencia de que en la actualidad hay muchos jóvenes con formación que se trasladan de economías deprimidas en busca de oportunidades en centros económicos emergentes. En vez de volver a asumir patrones imperiales del pasado, esto refleja las constelaciones cambiantes de una economía global que ya no está dominada por una sola superpotencia. 
En general, los patrones de desventaja y diferenciación en el mercado laboral que se han establecido en años pasados han tenido profundos efectos durante la CEG. Los migrantes han sido particularmente impactados por el desempleo y por las caídas en los ingresos. Además, los nuevos puestos de trabajo que se crearon al mejorar las condiciones económicas han sido en gran medida temporales o informales, reduciendo aun más la seguridad en el empleo. No obstante, la lección más importante de la CEG consistió en que los trabajadores migrantes eran esenciales para las economías de los países industriales, especialmente en Europa y algunos países asiáticos, donde el cambio demográfico está llevando a una fuerza de trabajo local en declive. En general, las reservas de migrantes no se han reducido y están surgiendo nuevos patrones migratorios en respuesta a los importantes cambios en la estructura de la economía mundial.

\section{Conclusión}

Nunca ha habido una clase trabajadora homogénea en el capitalismo. Los trabajadores siempre han provenido de diversos antecedentes culturales y sociales, $y$ han tenido diferentes aspiraciones y estrategias de vida. En el lugar de trabajo, los patrones han tratado a los seres humanos como portadores de fuerza de trabajo, aunque al mismo tiempo han dividido a la población laboralmente activa siguiendo criterios como género, raza, grupo étnico, edad, orígenes y estatus legal. En diversas épocas, términos como fuerza de trabajo no libre, sexismo, racismo, discriminación, precariedad y negación de los derechos humanos y de los trabajadores han sido utilizados por los críticos para caracterizar estos procesos. No hemos de argumentar en torno a la terminología: el punto medular es el de los mecanismos de diferenciación que llevan a la inequidad y las divisiones entre la gente que trabaja. Estos mecanismos han sido cruciales en cada etapa del desarrollo capitalista, incluyendo la etapa más reciente: el surgimiento de un mercado de trabajo global neoliberal. 
En este artículo se ha dejado sin abordar - por razones de espacio- un tema crucial. En conclusión, empero, quiero llamar la atención sobre la importancia de la agencia humana y de la resistencia en contra de la diferenciación y la división (véase el excelente y detallado análisis de Taran, 2012). Podemos verlo en el nivel individual, por ejemplo, en la negativa de los migrantes a salir de Europa después de 1973 o en las decisiones de iniciar la migración irregular a pesar de los enormes riesgos. También podemos verlo en un nivel colectivo en las luchas de los trabajadores migrantes en contra de las horrendas condiciones de trabajo en Dubai y en otros Estados del Golfo desde mediados de la primera década del siglo, en la movilización de los migrantes en Estados Unidos en contra de la legislación represora en 2006, o en la lucha a favor de los derechos de las trabajadoras domésticas migrantes en Hong Kong. Hay muchos otros ejemplos. Los sindicatos, que deberían haber estado a la cabeza en el reclamo de derechos iguales para todos los trabajadores, han sido ambivalentes: algunos sindicatos han asumido esta lucha, mientras que otros parecen funcionar como círculos cerrados de los grupos más privilegiados que excluyen a los trabajadores en desventaja. En respuesta a esta ambivalencia, los migrantes en todas partes han formado sus propias asociaciones y está surgiendo un movimiento de la sociedad civil global a favor de los derechos de los trabajadores. Estas importantes tendencias no pueden ser analizadas aquí, pero no hemos de suponer jamás que los mecanismos de diferenciación, que son tan importantes para el neoliberalismo, quedarán sin ser cuestionados.

\section{REFERENCIAS}

Abella, Manolo y Geoffrey Ducanes (2009), Technical note: the effect of the global economic crisis on Asian migrant workers and governments' responses, Bangkok, ILo Regional Office for Asia and thePacific, http:// www.age-of-migration.com/uk/financialcrisis/updates/1d.pdf> (consulta: 3 de septiembre de 2012). 
Alba, Francisco (2010), Mexico: a crucial crossroads, Washington, Migration Information Source, http://www.migrationinformation.org/Profiles/ display.cfm? $\mathbf{I D}=772$ ( (consulta: 9 de marzo de 2010).

Anderson, Bridget (2000), Doing the Dirty Work: The Global Politics of Domestic Labour, Londres, Zed Books.

(2007), «A Very Private Business: Exploring the Demand for Migrant Domestic Workers», European Journal of Women's Studies, volumen 14 , número 3.

Appleyard, Reginald T. (1991), International Migration: Challenge for the Nineties, Ginebra, International Organisation for Migration.

Bhagwati, Jagdish (2003), «Borders Beyond Control», Foreign Affairs, volumen 82, número 1.

Blackburn, Robin (1988), The Overthrow of Colonial Slavery 1776-1848, Londres y Nueva York, Verso.

BorJas, George J. (1990), Friends or Strangers: The Impact of Immigration on the us Economy, Nueva York, Basic Books.

Canagarajah, Sudharshan y Martin Kholmatov (2010), Migration and remittances in CIS countries during the Global Economic Crisis, Washington sc, World Bank, http://www.worldbank.org/eca> (consulta: 6 de abril 2012).

Castres, Stephen, Magdalena Arias Cubas, Chulhyo Kim y Derya Ozkul (2012), «Irregular migration: causes, patterns and strategies» en Irena Omelaniuk y National Institute for Migration Mexico (INAmI) (editores), Reflections on Migration and Development, Berlin y Geneva, Springer and International Organization for Migration.

y Godula Kosack (1973), Immigrant Workers and Class Structure in Western Europe, Londres, Oxford University Press.

y Mark J. Miller (2009), The Age of Migration: International Population Movements in the Modern World Fourth edition, Basingstoke y Nueva York, Palgrave, Macmillan and Guilford.

Clandestino (2009), «Comparative Policy Brief-Size of Irregular Popula-

$38 \triangleleft$ MIGRACIÓN Y DESARROLLO, VOL. 11, NÚM. 20, PRIMER SEMESTRE DE 2013 
tion», Hamburg: Clandestino Research Project, http://clandestino.eliamep.gr (consulta: 9 de marzo de 2010).

Conen, Robin (1987), The New Helots: Migrants in the International Division of Labour, Aldershot, Avebury.

(1991), «East-West and European Migration in a Global Context», New Community, volumen 18, número 1.

(1995), «Asian Indentured and Colonial Migration» en R. Cohen (editor), The Cambridge Survey of World Migration, Cambridge, Cambridge University Press.

Collins, Jock (1991), Migrant Hands in a Distant Land: Australia's Post-war Immigration second edition, Sydney, Pluto Press.

Cox, Rosie (2006), The Servant Problem: Domestic Employment in a Global Economy, Londres y Nueva York, I. B. Tauris.

Engels, Frederick (1962), «The Condition of the Working Class in England», Marx and Engels on Britain, Moscú, Foreign Languages Publishing House.

Esping-Andersen, Gøsta (1990), The Three Worlds of Welfare Capitalism, Oxford, Polity Press.

GoLDRING, Luin y Patricia Landolt (2011), «Caught in the work-citizenship matrix: the lasting effects of precarious legal status on work for Toronto immigrants», Globalizations, volumen 8, número 3.

Hammar, Tomas (1990), Democracy and the Nation-State: Aliens, Denizens and Citizens in a World of International Migration, Aldershot, Avebury. Huang, Shirlena, Leng Leng Thang y Mika Toyota (editores) (2012), Global Networks, Special Issue, Transnational Mobilities for Care, Rethinking the Dynamics of Care in Asia, Oxford y Malden MA, Blackwell. ,Brenda S. A. Yeoh y Noor Abdul Rahman (2005), Asian Women as Transnational Domestic Workers, Singapore, Marshall Cavendish Academic.

Hunger, Uwe y Dietrich Thränhardt (2001), «Die Berliner Integrationspolitik im Vergleich der Bundesländer» en Frank Gesemann (editor), Migration und Integration in Berlin, Opladen, Leske und Budrich. 
IOM (2011), World Migration Report 2011: Communicating Effectively about Migration, Geneva, International Organization for Migration.

JAckson, John Archer (1963), The Irish in Britain, Londres, Routledge and Kegan Paul.

Lenin, Vladimir Ilich (1968), Imperialism the highest stage of capitalism, Moscú, Progress Publishers.

Lucassen, Jan (1995), «Emigration to the Dutch colonies and the USA» en Robin Cohen (editor), The Cambridge Survey of World Migration, Cambridge, Cambridge University Press.

Marx, Karl (1976), Capital I, Harmondsworth, Penguin.

Milanovic, Branko (2007), «Globalization and inequality» en David Held y Ayse Kaya (editores), Global Inequality: Patterns and Explanations, Cambridge y Malden MA, Polity.

Mohapatra, Sanket, Dilip Ratha y Ani Silwal (2011), Outlook for Remittance Flows 2012-14 Migration and Remittances Unit Migration and Development Brief, Washington Dc, World Bank, http://siteresources.worldbank.org/InTPROS PECTs/Resources/334934-1110315015165/MigrationandDevelopmentBrief17.pdf (consulta: 23 de diciembre de 2011).

NaYar, Deepak (1994), «International labour movements, trade flows and migration transitions: a theoretical perspective», Asian and Pacific $M i-$ gration Journal, volumen 3, número 1.

Ness, Immanuel (2005), Immigrants, Unions and the New U.s. Labor Market, Filadelfia, PA, Temple University Press.

ocde (2007), International Migration Outlook: Annual Report 2007, París, Organisation for Economic Cooperation and Development.

ocDE (2011), International Migration Outlook: SOPEMI 2011, París, Organisation for Economic Co-operation and Development.

Passel, Jeffrey S. y D’Vera Cohn (2011), «Unauthorized Immigrant Population: National and State Trends 2010», Washington Dc, Pew Hispanic Center, ‘http://pewhispanic.org/reports/report.php?ReportID=133 (consulta: 15 de julio de 2011). 
Phillips, Nicola (2011), «Migration and the global economic crisis», en Nicola Phillips (editor), Migration in the Global Political Economy, Boulder Co, Lynne Rienner.

Phizacklea, Annie (1990), Unpacking the Fashion Industry: Gender Racism and Class in Production, Londres, Routledge.

Piper, Nicola (2011), «Towards a gendered political economy of migration» en Nicola Phillips (editor), Migration in the Global Political Economy, Boulder, Co., Lynne Rienner.

Polanyi, Karl (2001), The Great Transformation: the Political and Economic Origins of Our Time, 2nd Beacon Paperback, Boston, Beacon Press.

Portes, Alejandro y Rubén G. Rumbaut (2006), Immigrant America: a Portrait, third edition, Berkeley, University of California Press.

RATH, Jan (2002), Unravelling the Rag Trade: Immigrant Entrepreneurship in Seven World Cities, Oxford, Berg.

ReYNeri, Emilio (2003), «Immigration and the underground economy in new receiving South European countries: manifold negative effects, manifold deep-rooted causes», International Review of Sociology, volumen 13, número 1.

y Giovanna Fullin (2010), «Labour market penalties of new immigrants in new and old receiving West European countries», International Migration, volumen 49, número 1.

Sassen, Saskia (1988), The Mobility of Labour and Capital, Cambridge, Cambridge University Press.

Schierup, Carl Ulrich y Stephen Castles (2011), «Migration, minorities and welfare» en N. Phillips (editor), Migration in the Global Political Economy, Boulder y Londres, Lynne Rienner.

, Peo Hansen y Stephen Castles (2006), Migration, Citizenship and the European Welfare State: A European Dilemma, Oxford, Oxford University. Shimpo, Mitsuru (1995), «Indentured migrants from Japan» en Robin Cohen (editor), The Cambridge Survey of World Migration, Cambridge, Cambridge University Press. 
Sмiтн, Hazel (2012), «Europeans seek richer pastures», Guardian Weekly, Londres, 30 de diciembre-5 de enero 2012.

Standing, Guy (2011), The Precariat: the New Dangerous Class, Londres, Bloomsbury.

Taran, Patrick (2012), «Crisis, Migration and Precarious Work: Impacts and Responses-Focus on European Union member countries», Geneva, Global Migration Policy Associates, «www.globalmigrationpolicy. org〉 (consulta: 16 mayo de 2012).

us Department of Labor (1989), «The Effects of Immigration on the us Economy and Labor Market», Us Government Document, Washington DC. 